This item was submitted to Loughborough's Research Repository by the author.

Items in Figshare are protected by copyright, with all rights reserved, unless otherwise indicated.

\title{
Muscle recruitment and stone tool use ergonomics across three million years of Palaeolithic technological transitions
}

PLEASE CITE THE PUBLISHED VERSION

https://doi.org/10.1016/j.jhevol.2020.102796

\section{PUBLISHER}

Elsevier

VERSION

AM (Accepted Manuscript)

\section{PUBLISHER STATEMENT}

This paper was accepted for publication in the journal Journal of Human Evolution and the definitive published version is available at https://doi.org/10.1016/j.jhevol.2020.102796.

LICENCE

CC BY-NC-ND 4.0

\section{REPOSITORY RECORD}

Key, Alastair JM, lan Farr, Robert Hunter, and Sam Winter. 2020. "Muscle Recruitment and Stone Tool Use Ergonomics Across Three Million Years of Palaeolithic Technological Transitions". Loughborough University. https://hdl.handle.net/2134/12951521.v1. 
4 Keywords: Surface electromyography; lithic function; Lower Palaeolithic; Levallois; cutting 5

\section{Muscle recruitment and stone tool use ergonomics across three million years of Palaeolithic technological transitions}

\section{Abstract}

Ergonomic relationships that minimise muscle activity relative to the creation of cutting stress underpin the design of modern knives, saws and axes. The Palaeolithic archaeological record, and the $>3$ million years of technological behavior that it represents, is predominantly characterised by sharp stone implements used for cutting. To date, we do not know whether Palaeolithic hominins adhered to ergonomic principles when designing stone tools, if lithic technological transitions were linked to easeof-use advances, or even how muscularly demanding different Palaeolithic tools are on an empirically defined relative basis.

Here, we report the results of an experimental program that examines how four key stone tool types, produced between $\sim 3.3$ million to $\sim 40$ thousand years ago, influence muscle activation in the hominin upper limb. Using standardized laboratory-based tests designed to imitate Pleistocene cutting behaviors, surface electromyography recorded electrical activity (amplitude) in nine muscles across the hand, forearm and shoulder of modern humans during the use of replica Lomekwian, Oldowan, Acheulean and Mousterian stone tools. Results confirm digit flexors and abductors, particularly the first dorsal interosseous and flexor pollicis longus, to be the most heavily recruited muscles during the use of all tool types. Significant differences in muscle activation are, however, identified dependent on the type of stone tool used. Notably, the abductor digiti minimi, flexor pollicis longus, and biceps brachii were highly activated during handaxe use, particularly when compared to the use of Oldowan and Levallois flakes. Results are discussed in light of current understanding on the origin of Lower and Middle Palaeolithic technologies, why specific tool types were produced over others during these periods, and the extent to which early hominins produced ergonomically designed tools. 


\subsection{Introduction}

Hominins have relied on hand-held cutting-implements for over three million years. By facilitating access to food resources, providing a means to produce tools and clothing, and opening up new and otherwise inaccessible ecological niches, cutting-tools allowed Palaeolithic populations to spread throughout the Old World and colonize the vast interior of the Americas (Isaac, 1989; Ambrose, 2001; Eren, 2013; Dennell, 2017; Shea, 2017). Indeed, they were, and still are, essential for our survival.

Since the emergence of Palaeolithic archaeology as a discipline, people have sought to understand why one type or form of stone cutting-tool was produced over another (Boucher de Perthes, 1847; Evans, 1872; Ashton and McNabb, 1994; Key and Lycett, 2017a). Frequently these questions manifest themselves chronologically, with the observation that different stone technologies replaced and, presumably, were favored over other earlier types and forms (Isaac, 1969; Bar-Yosef, 1998; Ambrose, 2001; Foley and Lahr, 2003; Gowlett, 2009; Ollé et al., 2013; Shea, 2017). These technological and morphological transitions are often most clearly defined prior to the emergence of the Upper Palaeolithic.

The first flaked stone tool industry, the Lomekwian (Harmand et al., 2015), is currently known from a single 3.3 million-year-old locality in West Turkana, Kenya. Large flake implements $(>10 \mathrm{~cm})$ with sharp edges suitable for cutting, produced through passive hammer and/or bipolar techniques, characterise these tools (Lewis and Harmand, 2016). By 2.6 Ma Oldowan stone technologies, associated with the production of flake cutting tools $3-5 \mathrm{~cm}$ in length and displaying the intentional production of sharp cutting edges (Toth, 1985; Roche, et al., 1999; Rogers and Semaw, 2009; Braun et al., 2019), come to dominate the archaeological record. Although these 'basic' flake tools continue to be produced throughout the Palaeolithic, the emergence of bifacially flaked large cutting tools (LCTs) during the Acheulean period ( 1.75-0.3 Ma) represents a new level of investment and design intent in cutting technologies (Isaac, 1969; Goren-Inbar and Saragusti, 1996; Lycett and Gowlett, 2008; Semaw et al., 2009; Sharon, 2010; Wynn and Gowlett, 2018). Acheulean LCTs, principally characterized by handaxes and cleavers, are subsequently replaced as the foci of cutting technologies by Middle Palaeolithic (Mousterian) Levallois tools $\sim 300 \mathrm{Ka}$ (Moncel et al., 2011; Tron and Faith, 2013). Levallois flake tools, produced through predetermined hierarchical reduction strategies (Boëda, 1995; Brantingham and Kuhn, 2001; Eren and Lycett, 2012), vary in size (typically 3 - 15 cm in length [e.g. Tryon et al., 2006]) but characteristically display substantial lengths of effective cutting edge around their circumference (Brantingham and Kuhn, 2001; Eren and Lycett, 2016). Subsequent to the emergence of Late Middle and Early Upper Palaeolithic technologies there is increased complexity in the number of cutting-tool types produced, and finer chronological and geographic gradation between technological foci (Camps and Chauhan, 2011; Bicho et al., 2015). 
Why Lower and Middle Palaeolithic hominins replaced one type or form of stone technology with another has been discussed from diverse perspectives, in part due to the substantial variation that exists in how and when these transitions occurred across the Old World. Previous research includes investigation into hominin cognitive and anatomical capabilities (Wynn and Coolidge, 2004; Stout et al., 2008; Faisal et al., 2010; Shipton, 2016; Key and Lycett, 2018; Key and Dunmore, 2018; Pargeter et al., 2019), varying ecological contexts and the relevance of different tool-use performance characteristics (McNabb, 2005; Shea, 2007; Rogers and Semaw, 2009; Shipton et al., 2013; Galán and Dominguez-Rodrigo, 2014; Iovita, 2014; Key and Lycett, 2017b, 2017c; Bilbao et al., 2019), raw material economic strategies (Brantingham and Kuhn, 2001; Muller and Clarkson, 2016; Lin et al., 2018; Rezek et al., 2018), and population dynamics alongside the impact of socially mediated cultural transmission mechanisms (Clark, 1987; Van Peer et al., 2003; Lycett et al., 2010; Moncel et al., 2012; Lycett and Eren, 2013; Adler et al., 2014; Milhailovic and Bogicevic, 2017; Malinsky-Buller, 2016), among others.

Equally, the idea that Lower and Middle Palaeolithic technological transitions coincided with improvements to the ergonomic design of stone tools has been raised (e.g. Grosman et al., 2011; Eren and Lycett, 2012; Wynn and Gowlett, 2018). That is, new stone technologies may have come to dominate over previous alternatives because of their increased ease of use when held by the hand. No studies have explicitly tested such hypotheses (although for tool production examples see Faisal et al. [2010] and Key and Dunmore [2018]), but research concerning the evolution of the human hand (Marzke and Shackley, 1986; Marzke, 1997; Rolian et al., 2011; Key and Lycett, 2018; Williams-Hatala et al., 2018) or stone tool gripping strategies (Borel et al., 2016; Key et al., 2018a) has indirectly examined tool-use ergonomics in different lithic technologies. Williams-Hatala et al. (2018), for example, identified manual pressures incurred during percussive marrow extraction, a stone tool behaviour likely to have occurred prior to $3.3 \mathrm{Ma}$, to be significantly greater than those observed during flake and handaxe use. Meanwhile, Rolian et al. (2011) suggested that hominins were likely to experience increased biomechanical stresses during Oldowan flake-tool use relative to larger stonecutting technologies (e.g. Lomekwian flakes, handaxes). There are, however, potential difficulties aligning experimental data derived from modern humans with technological transitions enacted by extinct hominins with (at times) distinct upper limb anatomy. Species with relatively small manual dimensions (e.g. Homo naledi, Australopithecus sediba), for example, could have automatically incurred increased musculoskeletal stresses when using larger tool types (Key and Lycett, 2018).

Archaeological studies often compare the functional performance of different Lower and Middle Palaeolithic stone tool types and forms (e.g. Jones, 1981; Jobson, 1986; McCall, 2005; Prasciunas, 2007; Shea, 2007; Galán and Domínguez-Rodrigo, 2014; Key et al., 2016; Key and Lycett, 2017b; Bilbao et al., 2019), but ergonomic considerations are almost exclusively based on subjective observations by 
tool users or derived inferences. McNabb (2005: 292) provides a typically characteristic and widely expressed example when stating 'at the most basic level the biface provides a large cutting tool which is easier to hold [than a flake]. Its size allows the worker to maintain a secure grip and apply continued pressure especially when the tool has become slippery as blood, fat and other animal products adhere to the tool's surface during butchery'. Other works have inferred there to be ergonomic design features in Palaeolithic technologies through morphological, usewear and technological analyses of artefacts (e.g. Kleiniest and Keller, 1976; Phillipson, 1997; Tomka, 2001; Gowlett, 2006; Archer and Braun, 2010; Grosman et al., 2011; Eren and Lycett, 2012; Rots, 2013; Claud, 2015; Baena et al., 2016; Zupancich et al., 2016; Hardy et al., 2018; Wynn and Gowlett, 2018; Viallet, 2019). In many cases we agree with these statements and inferences, but to date these hypotheses remain untested using empirical musculoskeletal data derived from experiments or biomechanical modelling.

Electromyography (EMG), a technique which uses surface or intramuscular sensors to record electrical activity (potential) during muscular contractions, is routinely applied during ergonomic investigations of modern hand-held tools (e.g. Grant and Habes, 1997; Freund et al., 2000; Gazzoni et al., 2016). Increased electrical activity, which indicates increased muscle force output achieved by an increase in motor nerve firing (Milner-Brown et al., 1973), demonstrates muscles to be working harder during the use of specific tool types or forms. Archaeological and anthropological research has yet to widely incorporate EMG techniques; only the pioneering work of Hamrick et al (1998) and Marzke et al. (1998) have done so in relation to stone tools. Marzke et al. (1998) used intramuscular EMG to investigate electrical activity in 17 hand muscles during the production of replica Oldowan flake tools. They identified the flexor pollicis brevis, flexor carpi ulnaris, first dorsal interosseous, second flexor digitorum profundus and fifth flexor digitorum profundus to be heavily recruited and essential for effective stone tool production. Hamrick et al (1998) investigated the use of flake stone tools, but only did so for the flexor pollicis longus (FPL), and only compared flake tool use to hammerstone use or 'fine manipulation' behaviours. They identified FPL electrical activity to increase in line with resistance to the thumb's volar pad, but conclusions concerning which tool-use behavior more heavily recruited the FPL were participant dependent. Despite requirements for additional EMG tool-use investigations being noted at the time (Markze et al., 1998), no other studies have been published (although also see Feuerriegel [2016]).

Our understanding of tool-use ergonomics through the Lower-to-Middle Palaeolithic period, and how they may have informed changes in technology are, therefore, limited. Here, we report the first largescale analysis of muscle activation during the use of multiple stone tool types spanning the Lower and Middle Palaeolithic. Using surface electromyography (sEMG), we investigate nine muscle in the upper limb of 30 modern humans while they use replica Lomekwian, Oldowan, Acheulean and Mousterian 
stone tools. Results provide the first data-driven ergonomic perspective on the invention and persistence of multiple Lower and Middle Palaeolithic stone technologies.

\section{0 Methods}

\subsection{Recording muscle activity}

During contraction, muscle fibers produce electrical signals through the propagation of intracellular action potential (IAP). The electrical potential field generated by IAP in the outer fibers of muscles can, in turn, be recorded by electrodes attached to the skin's surface (ionic current in the muscles is converted into a flow of electrons in the electrode). Here, sEMG was employed to record electrical activity at nine muscles sites on the dominant upper limb during stone tool use. Silver chloride $(\mathrm{AgCl})$ adhesive bipolar surface electrodes ( $24 \mathrm{~mm}$ diameter) were attached to the skin relative to the respective muscle belly according to international sEMG standards and SENIAM guidelines (Hermens et al., 2000; Stegeman and Hermens, 2007). Signals for each electrode pair were amplified using a gain of between 500 and $2000 \mathrm{~V} / \mathrm{V}$ (participant dependent), sampled at $2048 \mathrm{~Hz}$, and converted to digital data using a 12-bit analog-to-digital converter (EMG-USB2+, OT Bioelettronica, Torino, Italy; bandwidth 10-500 Hz). All signals were acquired in OT BioLab software.

The nine target muscles, their location, the site of sensor placement, and each muscle's movement action are detailed in Table 1 and Figure 1. Investigated muscles include those important to stone tool use and the unique manipulative capabilities of modern humans (e.g. flexor pollicis longus, abductor digiti minimi), those essential to ours and other primates gripping capabilities and manual dexterity (e.g. flexor pollicis brevis, flexor carpi radialis), and those associated with broader ranges of motion in the upper limb (e.g. brachioradialis, biceps brachii) (Marzke et al., 1998; Diogo et al., 2012). Due to the first dorsal interosseous', flexor pollicis brevis' and abductor digiti minimi's small size, electrodes at these target sites were cut in half such that both could be placed above the muscle (Fig. 2).

The volume and characteristics of tissues (skin, subcutaneous fat etc.) separating muscle fibers from electrodes have potentially large deforming and filtering effects on sEMG signals. We followed wellestablished protocols to minimise these effects (Hermens et al., 2000; Farina et al., 2016; Merletti et al., 2016). Prior to sensor attachment hair was removed from each site using a razor and cleaned using $70 \%$ isopropyl alcohol swabs. Filtering effects are minimized by bipolar electrode spatial filtering, however, additional controls included the standardization of electrode size, inter-electrode distances, and their attachment being performed by the same experienced individual (IF). Crosstalk between neighboring muscles is dependent on the target site, and is not likely to have had substantive impact on recordings from large muscles or those isolated by other tissues. Following sensor positioning, visual checks of each signal channel were performed to ensure absence of cross-talk when contracting individual muscles. The flexor pollicis brevis experienced a degree of crosstalk from the abductor pollicis brevis 
that could not be controlled for (although this is consistent for all participants and tools). Finally, as far as was practical the experiment was conducted away from other electrical sources to minimise interference potential. The amplifier was located behind participants and a reference electrode was dampened with water and placed around the wrist of the non-dominant arm.

\section{2 sEMG data}

Muscular activity is recorded here as both a raw measure of amplitude, in this case the signal's root mean square (RMS), and amplitude normalized as a percentage of that recorded during maximum voluntary contractions (\% MVC). Six MVC exercises were recorded from each participant prior to tools being used, capturing MVC amplitude for each of the nine muscles under investigation here to contextualise the RMS values reported for each muscle (Supplementary Online Material (SOM) Table $\mathrm{S} 1$ ). Increases in amplitude of sEMG signals (i.e. signal strength) indicate the activation of additional motor units, alongside modulation of IAP discharge rates (Fig. 3). The force created by muscles is similarly dependent on motor unit recruitment and IAP discharge. In some muscles, such as those controlling the fingers, the relationships between EMG amplitude and force can be considered linear (Clancy et al., 2016; Enoka and Duchateau, 2016). Hence, RMS and \% MVC can also provide information about muscle contraction 'strength'.

Prior to RMS values being calculated, band pass filtering (double passed [zero-lag] $2^{\text {nd }}$ order digital Butterworth filter) between $10 \mathrm{~Hz}$ to $350 \mathrm{~Hz}$ was applied to all raw signals (Fig. 3). These standard filtering parameters remove possible movement artefacts associated with whole body movement (not the contraction of targeted muscles) and possible high frequency noise. RMS values were calculated individually for $0.4 \mathrm{~s}$ time 'epochs' within each recorded sEMG signal, thus providing a degree of smoothing to reduce signal variability (Fig. 3). For example, during a 30 second period 75 RMS values would be calculated. Only RMS data that related to periods of stone tool-use were analyzed. Digital videos were used to precisely define tool-use periods within data streams, or alternatively, when participants rested, readjusted their body, or were waiting to start the task. A single individual (AK) assessed all videos. In instances where participants briefly paused during the task, RMS values from the period of cessation were removed from the analyzed data. On occasion, tools exerted considerable pressure on the superior surface of the flexor pollicis brevis sensor due to the use of the thenar eminence during five-jaw buttressed pad-to-pad grips, among others (very occasionally similar pressures occurred at other target sites) (for grip descriptions see: Marzke, 1997; Key et al., 2018). This resulted in signal clipping, saturation or motion artefact distortion (Fig. 3). If $<25 \%$ of values in a trial displayed these features then these portions were cut and the remaining data were used. If $>25 \%$ of data were distorted then the whole trial was discarded from the study. Hence, data sets for individual target muscles can be below 30 . 
207

208

209

210

211

212

213

214

215

216

217

218

219

220

221

222

223

224

225

226

227

228

229

230

231

232

233

234

235

236

237

238

239

Muscle activation was investigated during the use of four stone tool types (Fig. 4). These tools span $>3$ million years of Plio-Pleistocene technological behavior, ranging from the earliest known intentionally fractured Lomekwian flake technology through to Mousterian Levallois flakes (Fig. 3). The four stone tool types utilized in this study are;

- Lomekwian large flake tools (LOM), as described by Harmand et al (2015).

- Oldowan flake tools (OLD), as outlined by Roche et al. (1999).

- Acheulean handaxes (ACH), as defined by Lycett and Gowlett (2008).

- Levallois flake tools (LEV), as described by Boëda (1995).

For each technology, 40 replica tools that conform to mass, size and shape ranges observed in the archaeological record were produced (a random sample of 30 were used). Descriptive morphological data for the utilized tool assemblages can be found in Table 2 .

Palaeolithic stone tools display morphological fluidity within and between technological categories and those utilized here broadly represent idealized forms that characterize their respective 'types'. The present study therefore focuses on differences between types of stone tool, and not variation observed within artefact classifications. Although there are multiple morphological and technological differences between the tool types used here, key differences include their gross size, the presence or absence of a 'globular butt' (c.f. Gowlett, 2006), the presence or absence of cutting edge scalloping, and a tool's elongation and weight.

Each experimental subject ( $\mathrm{n}=30 ; 11$ female, 19 male) was randomly assigned one tool from each of the four assemblages, with these four tools being used in a randomly assigned order (both designated using randomizer.org). Subjects were recruited from the student and staff population at the University of Kent. All but two individuals had no prior training or education regarding Palaeolithic technologies, and all were naïve of the aims of the experimental program (the majority were sports science graduate students). The manual strength of participants was variable, with mean and standard deviation values for pad-to-side pinch strength equalling $8.8 \mathrm{~kg}$ and $2.1 \mathrm{~kg}$, respectively (recorded using a pinch dynamometer). Informed consent was obtained prior to participation and all individuals received nominal remuneration for their time $(£ 10[\sim \$ 13])$.

Inevitably, all participants display modern human (H. sapiens) upper limb anatomy. The replica tools used in this experiment, however, represent artefacts produced by multiple hominin species across three million years. Given that soft tissue anatomy is rarely preserved in the fossil record it is hard to precisely define the accuracy with which results from this study can be applied to some hominin species. We would contend that for most Middle-to-Late Pleistocene populations there is enough evidence to suggest modern human-like manual capabilities and anatomy in these species (Marzke, 2013; Mersey 
et al., 2013; Ward et al., 2014; Kivell, 2015; Key and Lycett, 2018). Therefore, results can likely be applied to these populations with reasonable accuracy. Late Pliocene and early Pleistocene stone tool users, however, display more substantial anatomical differences compared to modern humans. Although fossil evidence indicates these earlier species (e.g. Au. afarensis) to be potential stone tool users (Marzke, 1983, 2013; Almécija and Alba, 2014; Feix et al., 2015; also see Domalain et al., 2017), suggesting the muscular architecture essential for stone tool use to be present, we would urge pragmatism in the application of our results to these species.

\subsection{Cutting task}

Consistent with previous research (Prasciunas, 2007; Key and Lycett, 2017b, 2018; Bilbao et al., 2019), the cutting task used modern industrially standardized materials so that conditions were identical for each stone tool. This provided high levels of internal validity (Lycett and Eren, 2013) and appropriately focused our investigation on differences between cutting implements and not the worked material (Eren et al. 2016; Lin et al. 2018). Following Key et al. (2016), all stone tools cut through a series of materials attached to a frame placed on the floor. A $70 \times 180 \mathrm{~cm}$ aluminium frame was custom built for the study and inclined on the floor at an angle of $15^{\circ}-20^{\circ}$ from vertical, such that it lent away from participants when they knelt beside it (Fig. 1). The frame had five sections and four unique cutting tasks. Before the use of each tool, individuals undertook practise cutting actions to familiarize themselves with how best to resist cutting forces and grip the tool. Individuals were required to use their dominant hand (selfreported) but were free to grip tools however they preferred. The non-dominant hand could be used to secure and/or steady the cut materials. All subjects were asked to perform the cutting task as quickly as possible, but were informed they must 'always remain in full control of the tool, and use a slicing cutting motion' (i.e. no cleaving or uncontrolled hacking).

Subjects were first required to cut a $90 \mathrm{~cm}$ long ' $\mathrm{S}$ ' shaped line, at a depth of $2 \mathrm{~cm}$, into a slab of pottery clay placed on a metal sheet secured by the aluminium frame (Fig. 1). Use of a stencil to lightly mark the line on the clay's surface ensured each cut was identical. The second section required subjects to cut through eleven 9-11 cm long segments of $4 \mathrm{~mm}$ thick, heavy duty, polypropylene twine arranged spherically and dissipating away from a central metal ring (Fig. 1). Five $16 \mathrm{~cm}$ segments of the same twine, secured vertically, formed the third cutting task section. Segments four and five were identical and consisted of ten $12 \mathrm{~cm}$ long twine segments secured horizontally. All twine segments were secured using plastic hooks attached to metal eye bolts. Task duration varied between participants and tool types, but typically took 1-3 minutes to complete. Subjects were given a 10-minute rest between each tool use event.

While these tasks do not directly recreate Palaeolithic cutting activities, they do replicate cutting motions consistent with butchery and woodworking activities (among others), enforce the use of varied and dynamic cutting motions in a naturalistic kneeling position, and allow data collection in a controlled 
and systematic manner. Moreover, differences between the present activities and some Palaeolithic cutting conditions are known, allowing material differences to be accounted for (Key et al., 2018b). To protect the hand and palmar sensors from damage a thin rubber glove was worn on the tool-using hand. Ethical approval was granted by the University of Kent School of Sports and Exercise Science (ref: prop 131_2016_17).

\subsection{Statistical analysis}

For every participant, mean RMS values were calculated for the nine target muscles during each tool use event (SOM Table S2). Due to signal strength variation and site dependent filtration / deforming effects on sEMG signals raw amplitude data (i.e. RMS) are not directly comparable between different target muscles. Hence, mean RMS values are used here to compare between activation levels for specific muscles dependent on the stone tool being used. Analysis of variance (ANOVA) tests were used to investigate which stone tools recruited individual muscles to a greater or lesser extent, as defined by mean RMS values, during the use of Lomekwian, Oldowan and Levallois flakes and Acheulean handaxes $(\alpha=.05)$. Tukey's honest significance difference (HSD) post hoc tests were used to identify where any significant differences may lie $(\alpha=.05)$.

MVC normalised amplitude values, where mean RMS values are expressed as a percentage of mean MVC RMS values (\% MVC), facilitate comparison of recruitment levels between muscles during stone tool use events. This makes it possible to see, on a relative basis, which of the nine target muscles are recruited most heavily during stone tool use, and how this varies dependent on the type of tool being used. Percentile data is not continuous, often bounded (here, only by a lower threshold), and in some instances, data here were not normally distributed (revealed by Kolmogorov-Smirnov tests). In turn, Kruskal-Wallis tests were used to identify whether significant \% MVC differences exist between muscles during the use of each tool type $(\alpha=.05)$. To identify where any significant differences may lie (if there are any), post hoc Mann-Whitney U tests were run between individual muscle's \% MVC values.

Supplementary to the ANOVA tests comparing activation levels for individual muscles, dependent on the type of stone tool used, Kruskal-Wallis tests and post-hoc Mann-Whitney U tests using \% MVC values were also performed. These repeat tests investigate the same question, but use normalised amplitude values to support those performed using RMS data. All data were analysed using PAST (version 3.25).

\subsection{Results}

\subsection{Impact of tool type on muscle activation}

ANOVA tests reveal sEMG signal amplitude to vary significantly for the abductor digiti minimi, dependent on the type of stone tool used (Table 3). This was consistent for both the clay and rope cutting 
tasks. Post-hoc Tukey's HSD tests identified handaxes to display significant greater abductor digiti minimi RMS values relative to both Oldowan and Levallois flakes (SOM Table S3).

No other ANOVA tests between tool types returned significant differences in muscle RMS values at a 95\% confidence interval (Table 3). Both the flexor pollicis longus and biceps brachii, however, displayed values approaching significance during the clay-cutting task. Post-hoc Tukey HSD tests using RMS data identified handaxes as displaying significantly greater values relative to Levallois flakes for the flexor pollicis longus during this task, but no significant differences between any tools for the biceps brachii (SOM Table S3). Supporting Kruskal Wallis tests performed using normalised \% MVC data did, however, identify significant differences in flexor pollicis longus and biceps brachii activation dependent on the stone tool being used (SOM Table S4). The associated supporting post-hoc Mann Whitney U tests (using \% MVC data) similarly only suggest significant differences in activation levels for the abductor digiti minimi, flexor pollicis longus and biceps brachii (SOM Table S5). All three muscles identified handaxes as requiring significant greater activation (\% MVC) compared to Oldowan and Levallois flakes (SOM Table S5). The FLP also identified a significant difference between Levallois and Lomekwian flakes, while the BB displayed significant differences between Oldowan and Lomekwian flakes (Lomekwian flakes returned greater values in both cases). In sum, only abductor digiti minimi, flexor pollicis longus and biceps brachii activation was significantly affected by the type of stone tool used.

\subsection{Relative muscle activation across the arm}

Comparisons of muscle \% MVC values using Kruskal Wallis tests, run independently for the four stone tool types and the two cutting tasks, returned significant differences in all instances (Table 4). The nine target muscles were, therefore, recruited to significantly different extents during the experimental task.

Post-hoc Mann-Whitney U tests elucidate these differences, and when combined with descriptive data reveal which specific muscles were used to a significantly greater or lesser extent (SOM Tables S2 and S6). The most heavily recruited muscles are responsible for flexion, adduction or abduction of the digits and in-hand manipulation. Of these, the first dorsal interosseous and flexor pollicis longus display the greatest \% MVC values across all tool types in most instances, and are thus on a relative basis the most heavily recruited muscles investigated here. While there are differences dependent on the specific tool used or cutting task undertaken, the FDI and FPL were most often significantly greater than the FCR, B, BB, TB, and AD (SOM Table S6).

The flexor pollicis brevis was also heavily recruited, albeit usually to a lesser extent that the FDI and FPL (Fig. 5; SOM Table S1). Significant differences between the FPB and FCR, B, BB, TB, and AD are repeatedly observed, except during the rope-cutting task with the Levallois flake (SOM Table S6). The abductor digiti minimi is heavily recruited during the use of handaxes (Fig. 5; SOM Table S1), particularly during the clay task, where \% MVC values were significantly greater than those seen in the 
FCR, B, BB, TB and AD (SOM Table S6). The two smaller flake types (Oldowan and Levallois) recruit the ADM to a lesser extent (Fig. 5; SOM Table S1).

346 Muscles responsible for rotation and flexion of the hand at the wrist (flexor carpi radialis), flexion and 347 extension of the forearm (brachioradialis, biceps brachii, triceps brachii), and abduction of the 348 humorous (anterior deltoid) were less heavily recruited (Fig. 5; SOM Tables S2 and S6). In particular, the biceps brachii and brachioradialis typically displayed the lowest \% MVC values.

\subsection{Discussion}

351

352

353

354

355

Why Lower and Middle Palaeolithic hominins produced specific stone tool types for extended periods, or invented alternatives for existing technologies, are fundamental questions that have been investigated from diverse perspectives. Studies concerning manual-related aspects of these technologies have grown in number and complexity in recent years. Still, we know little about how ergonomic considerations influenced hominin stone tool production and use decisions. Here, we have taken a first step towards empirically defining the upper limb ergonomics of Lower and Middle Palaeolithic stone tool use.

\subsection{Impact of tool type on muscle activation}

Four types of stone tool were used in a standardized cutting task and their influence on electrical activity (amplitude) in nine upper limb muscles was recorded. Significant differences in muscle activation were identified between the four stone technologies. Foremost, abductor digiti minimi amplitude was highly dependent on the type of tool used, with handaxes requiring significantly greater activation levels, and therefore force outputs (Clancy et al., 2016; Enoka and Duchateau, 2016), relative to Oldowan and Levallois flakes. For the ADM then, handaxe use does not provide an ergonomic advantage relative to their technological precursor, Oldowan flakes. Levallois flakes, which come to prominence as characteristically 'Acheulean' handaxes start to occur less frequently in the archaeological record, do however present a benefit relative to this larger, earlier technology.

The heavy recruitment of the ADM during handaxe use is not surprising. Indeed, Marzke et al. (1998) reported high ADM activity in the non-dominant hand during stone tool production because of its important role stabilising the fifth digit, and in turn, ulnarly located portions of cores. Marzke and others also report that the fifth digit is only frequently recruited during the use of larger lithic technologies (Marzke and Shackley, 1986; Key et al., 2018a), due to its ability, when abducted using the ADM and flexed across the midpoint of the palm, to oppose the thumb and stabilise tools of this size. There are also indications of larger tools increasing loading on the fifth digit (Williams-Hatala et al., 2018), which in turn would place greater demands on the ADM. Combined, it is logical that the use of handaxes, a technology substantially greater in size and mass than smaller flake tools, would result in high ADM activation. 
Raw amplitude and MVC normalised data also reveal the flexor pollicis longus (FPL) to experience significantly greater activation during handaxe use compared to Levallois or Oldowan flakes. This indicates the first distal phalanx to be working harder to secure handaxes during cutting activities (Diogo et al., 2012). Again, then, the use of handaxes is not ergonomically beneficial relative to Oldowan or Levallois flakes and provides no ease-of-use advantages in terms of muscle activation. This finding corresponds with Williams-Hatala et al. (2018) who found pressure exerted and resisted by the first distal phalanx to be greater during handaxe use relative to small flake tool use. There are indications that Lomekwian flakes returned higher FPL activation levels relative to Levallois flakes, and thus may be more demanding to use. However, this was only significant during one cutting task using \% MVC data, and we urge caution when interpreting this result.

Biceps brachii (BB) activation altered in a similar manner to the ADM and FPL; that is, handaxe use elicited significant increases in amplitude, relative the use of Oldowan or Levallois flakes. Again then, handaxes provide a disadvantage relative to smaller flake tools. The role of the BB during stone tool use is not well understood as it does not directly contribute to in-hand manipulation of tools. Our finding that $\mathrm{BB}$ activation varies dependent on the type of stone tool used is, however, consistent with this muscle contributing to the effectiveness of a stone tool's use. We predict variation in BB activation to result from the distinct cutting motions required by each technology. Indeed, ergonomic research concerning modern metal cutting tools confirms BB activation and force output to be affected by grip choice, body posture, and cutting direction during butchery behaviors (Grant and Habes, 1997; Pontonnier et al., 2012). A handaxe's longer cutting edge allows for greater and potentially more forceful cutting motions that more heavily activate the $\mathrm{BB}$ as the tool is drawn towards and across the worked material. Smaller flake tools are more likely to recruit the BB in a stabilizing role, with wrist flexion drawing the tool across a worked material. Lomekwian flakes returned higher BB amplitude values compared to Oldowan flakes during the clay task; perhaps for similar reasons as handaxes. Significance at $\alpha=.05$ was, however, only just achieved and differences were not as strong as those observed for handaxes.

At a broad level, the differences in ADM, FPL and BB activation observed here likely result from tooltype size variation. Handaxes are substantially heavier and larger than Oldowan and Levallois flakes, have longer scalloped cutting edges, and facilitate force application away from the hand which results in torsion (Gowlett, 2006, 2013); features that could cause muscles to work harder when gripping a tool or applying it to cutting tasks (Key, 2016). Previous studies, however, suggest the precision grips associated with flake tools to elicit greater stresses in the first digit (Rolian et al., 2011), and hand musculature more generally (Tomka, 2001), relative to larger tool types. This is, in part, due to associated forces focusing on a few key manual areas (e.g. first volar pad, lateral side of second digit), while larger tools more evenly distribute forces across additional palmar aspects of the hand; as demonstrated by the recruitment of the ADM to secure handaxes. An inferred more secure and evenly 
413 distributed grip underlines many of the positive ergonomic connotations associated with handaxes (e.g. 414 Jones, 1981; McCall, 2005; Shea, 2007; Toth and Schick, 2009; Grosman et al., 2011; Key et al., 2016; 415 Viallet, 2016). Our results are not contradictory; increased contact between the hand and tool would 416 distribute stresses more evenly across the hand and increase the security of grips. Instead, our data 417 suggest that despite this, muscles still have to work harder to secure handaxes in the hand and apply 418 them to worked materials when compared to flakes. The few differences identified between Lomekwian 419 flakes, which were of comparable size to handaxes, and the other three tool types further suggests that 420 the specific shape of handaxes (i.e. elongation, edge scalloping) may also be playing a role. For example, their more obtuse edges relative to flake tools (Table 2) likely increased force requirements during use 422 (Key and Lycett, 2015). Although not explicitly tested here, we suspect Middle Palaeolithic handaxes 423 (e.g. Emery, 2010; Ruebens, 2013; Ashton and Scott, 2016) to present similar muscular demands to 424 their Acheulean counter parts; thus, being more demanding to use relative to contemporary Levallois flakes.

Six muscles were not significantly affected by tool-type changes, despite the size, shape and technological differences. This includes the first dorsal interosseous (DI) and flexor pollicis brevis (FPB) which abduct the second proximal phalanx / adduct the first metacarpal and flex the first metacarpal (respectively), allowing the thumb to forcefully oppose the fingers during stone tool grips. For these muscles, all four tools appear to be similarly demanding. This may, in part, reflect a balance between the demands of securing larger tools and the increased stresses on the first digit associated with precision grips. It is interesting that requirements for the first metacarpal to oppose the fingers remain relatively stable between tool types, despite the first distal phalanx being flexed with greater force during handaxe use. The lack of any differences for the brachioradialis (B), flexor carpi radialis (FCR), triceps brachii (TB) and anterior deltoid (AD) are less surprising. Their MVC \% values are substantially lower and any grip or cutting motion differences between tool types do not appear to be substantial enough to affect activation levels in these muscles.

\subsection{Muscle activation across the arm}

Our data confirm muscles responsible for digit flexion and in-hand manipulation to be highly activated during stone tool use. Expressed as a percentage of maximum voluntary contraction levels (\% MVC), mean values regularly exceeded $50 \%$ for the first DI, FPL and FPB, while the ADM ranged between $30-40 \%$. This compares to the more frequent occurrence of $10-30 \%$ of $\%$ MVC for the other five investigated muscles. Differences between muscles were significant in many instances. The muscles most heavily recruited during stone tool use are, therefore, those that secure tools within the hand and not those responsible for larger ranges of motion associated with cutting actions.

446 Of those examined, the FPL and first DI are the most heavily activated muscles across all four 447 technologies. Lower and Middle Palaeolithic cutting-tool use would therefore have likely relied heavily 
on these muscles, irrespective of the stone implement utilized. This is not surprising as the FPL inserts into the base of the first distal phalanx and is responsible for its forceful flexion during stone tool related grips (Marzke and Shackley, 1986; Marzke et al., 1998; Diogo et al., 2012). Our data supports Hamrick et al. (1998), who demonstrated the FPL to be highly activated during flake tool use, and corroborates previous research identifying high loading through the first distal phalanx during flake and handaxe use (Marzke, 1997, 2013; Rolian et al., 2011; Key and Lycett, 2018; Williams-Hatala et al., 2018). Moreover, the high FPL amplitude levels recorded here further underlines the important and forceful role of the first digit during stone tool use, and lithic technology's potential impact on the evolutionary trajectory of the hominin hand (Marzke, 1997, 2013; Kivell, 2015).

The first DI is as heavily recruited as the FPL, and both are activated more than the FPB and ADM (which are in themselves still highly activated). The high activation of the first DI is consistent with previous studies that note its essential role in adducting the thumb and bringing it into opposition with the fingers during stone tool use (Marzke et al., 1998; Marzke, 2013; Kivell, 2015). It is not that the FPB and AMD are not vital to the effective use of stone tools. Rather, on a relative basis, the FPL and first DI are the muscles most heavily recruited, those most likely to contribute to perceptions of 'easeof-use', and therefore the muscles most likely to influence tool design and use choices.

The FCR, B, BB, TB, and AD display much lower mean \% MVC levels relative to those contributing to the in-hand manipulation and gripping of tools. Again, this does not mean that they are not essential for stone tool use; after all, you cannot draw a tool across a worked material without triceps. Rather, these muscles are not heavily recruited relative to their potential activation levels and force output, and therefore, can easily cope with the associated muscular demands. Muscles directly responsible for gripping tools, particularly those responsible for flexion and adduction of the thumb (i.e. FPL and first DI), are therefore most likely to contribute to the ergonomic limits and preferences influencing Palaeolithic stone tool designs.

\subsection{Implications for technological change in the Lower and Middle Palaeolithic}

The Palaeolithic archaeological record does not often display geographically or chronologically uniform technological transitions. Nor does any single explanatory hypothesis account for these changes; although some variables are more relevant than others in specific circumstances. Constant throughout, however, is the fact that stone tools were held by the hand. Ergonomic considerations therefore had potential to influence technological transitions, tool preferences, and design features throughout the Palaeolithic.

\subsection{Lomekwian to Oldowan transition, or, large flake use versus small flake use}

The Lomekwian is currently a relatively poorly understood period, requiring additional sites to better 
Oldowan, however, is technologically well established and multiple sites indicate its origin $\sim 2.6$ million years ago in East Africa (Roche, et al., 1999; Rogers and Semaw, 2009; Braun et al., 2019). From a tool-use perspective, the Lomekwian's distinctiveness (as it is currently understood) relates to the large size of flake tools, which are often over $10 \mathrm{~cm}$ in length. Although similarly large flakes are on occasion found during the Oldowan (e.g. Leakey, 1971; Proffitt, 2018), mean tendencies are much smaller and

487

488

489

490

491

492

493

494

495

496

497

498

499

500

501

502

503

504

505

506

507

508

509

510

511

512

513

514

515

516 this difference requires explanation. Our data suggests there to be limited differences in muscle activation during the use of these two flake sizes. There was a single instance of Lomekwian flake's \% MVC being significantly greater than the smaller Oldowan alternative, but it only just reached significance ( $p=.0452)$ and was for the biceps brachii, one of the least heavily recruited muscles examined here. We therefore do not interpret this as strong evidence of Oldowan flakes displaying ergonomic benefits enough to prompt the invention and use of a new technology. Nor is there evidence that the use of different sized flakes (up to a limit) during either period would have substantially impacted muscle activation levels. Importantly, however, due to the duration of the cutting task our results cannot consider fatiguing and it is still possible for one flake type to display benefits over more extended durations.

\subsection{Oldowan to Acheulean transition, or, small flake use versus handaxe use}

Flake tools of variable size continue to be produced during the Acheulean, however, after $\sim 1.75$ Mya the production of handaxes is sustained and widespread across the Old World (Lycett and Gowlett, 2008). These large, bifacially flaked core tools represent a markedly more complex and demanding (time, raw materials, cognition) technology relative to flakes. Our results suggest that the invention and subsequent proliferation of handaxes is unlikely to be related to ease-of-use advantages during cutting tasks. Rather, we provide evidence to the contrary, demonstrating handaxe use to be more muscularly demanding relative to smaller flake tools. Relatively small 'Oldowan-like' flake tools would, therefore, have been beneficial to use when cutting materials of a similar volume and resistance to those examined here, promoting their production during the Acheulean. The invention and prolonged production of handaxes, by multiple hominin species, therefore requires an alternative explanation.

Functional advantages are still likely a primary cause underpinning the production of handaxes. These tools are known to be particularly effective compared to flakes during heavy-duty cutting tasks (Jones, 1980, 1994; Toth, 1985; Toth and Schick, 2009; Galán and Domínguez-Rodrigo, 2014; Key and Lycett 2017b), and the relative speed, reliability and efficacy of cutting behaviors has potential to be more advantageous to hominins (in some situations) in spite of any ergonomic costs (during the clay cutting task, for example, handaxes were $10-20 \%$ quicker than Oldowan and Levallois flakes). Moreover, particularly resistant or extended cutting tasks, such as woodworking behaviors, were not undertaken here. We think it likely that the increased cutting stress required to work hard materials would result in fore- and upper arm muscles contributing proportionately greater forces, and being more highly 
517 activated. Force transfer through the tool and onto the worked material would, in turn, be more easily 518 and comfortably facilitated by the greater tool-hand contact areas observed for handaxes (Marzke and 519 Shackley, 1986; Key et al. 2018a; Wynn and Gowlett, 2018). Further, we suspect that rates of muscle 520 fatiguing may differ between handaxes and smaller flake tools, with the former being of greater benefit 521 over extended duration. Within such contexts, handaxes still represent "an ergonomically guided 522 solution to the problem of producing a sturdy hand-held cutting tool" (Wynn and Gowlett, 2018: 27). 523 However, as with other recent studies, we also stress the potential influence of multiple other factors in 524 promoting handaxe production (Diez-Martín et al., 2015; de la Torre, 2016; Key and Lycett, 2017b; 525 Semaw et al., 2018; Wynn and Gowlett, 2018; García-Medrano et al., 2019; Herzlinger and Goren526 Inbar, 2019).

\subsection{Acheulean to Middle Palaeolithic transition, or, handaxe use versus Levallois flake use}

528 The Middle Palaeolithic transition is associated with the arrival of Levallois flakes, a variably sized 529 cutting technology (e.g. $3-15 \mathrm{~cm}$ in length) produced through predetermined hierarchical reduction 530 strategies (Boëda, 1995; Brantingham and Kuhn, 2001; Eren and Lycett, 2012). Although handaxes 531 continue to be produced during this period, Levallois technologies represent a widespread and sustained 532 phenomenon across the Old World that likely conveyed a benefit for hominins. Here we demonstrate 533 that Levallois flakes are ergonomically advantageous relative to handaxes when applied to a range of 534 cutting tasks, and thus may have been preferentially produced due to their lower muscular demands and 535 ease-of-use advantages. The context-specific functional benefits of handaxes over 'basic' flake tools 536 can, however, be similarly repeated for Levallois flakes; helping to explain the sustained production of 537 bifaces through the Middle Paleolithic (e.g. Reubens, 2013). However, there is nonetheless a clear 538 benefit to the use of Levallois flakes in some functional contexts. Our finding of no difference in muscle 539 activation between the Levallois and 'basic' (Oldowan) flakes is also important. Indeed, the invention 540 of Levallois flakes, and their production over more straightforward alternatives, cannot be attributed to 541 differences in their upper limb ergonomics (as revealed through muscular activation). Alternative 542 explanations must therefore continue to be emphasised (e.g. Eren and Lycett, 2016; Shimelmitz et al., 543 2016; Malinsky-Buller, 2016).

\subsection{Further considerations}

545 It is important to note that we have not investigated all stone tool types that emerged during the Lower 546 and Middle Palaeolithic. We focus on large flakes, 'basic flakes', handaxes and Levallois flakes because 547 they represent the technological foci of their respective periods and have consequently been the focus 548 of research seeking to explain changes in early human technological behavior. Attempts to understand 549 ergonomic-related behavioral changes across the Lower to Middle Palaeolithic should, therefore, first 550 start with these four technologies. Nonetheless, other stone tool technologies will likely recruit muscles 551 in variable ways and we cannot attest to how their production may have been affected by tool-use 
ergonomics. In a similar regard, the tool types investigated here were not highly variable in their shape or size. These additional factors and how they relate to ergonomic issues also require future clarification.

The nine muscles investigated here have allowed assessment of muscular activity across the upper limb of modern humans. Nonetheless, other muscles are linked to the effective use of stone tools (Marzke et al., 1998; Diogo et al., 2012) and it has yet to be seen how their activation is affected by the type of tool used. Moreover, in some respects the hominins responsible for using Lower and Middle Palaeolithic technologies would have displayed upper limb anatomy distinct to the modern humans in the present experiment (e.g. Niewoehner, 2001; Marzke, 2013; Mersey et al., 2013; Kivell, 2015; Tocheri et al., 2008; Domalain et al., 2017; Feuerriegel et al., 2019). It is not yet clear if the ergonomic relationships observed here would be represented in an identical manner in these other hominin species. For example, the more diminutive size of the $H$. habilis hand may have increased the muscular costs of using a handaxe (relative to Oldowan flakes) for this species (Key and Lycett, 2018). Modelling techniques (e.g. Domalain et al., 2017) combined with EMG data may provide one route to investigate such phenomenon.

\subsection{Conclusion}

Here we have taken a first step in investigating the upper limb ergonomics of hand-held Lower and Middle Palaeolithic stone tools. We use surface electromyography to demonstrate that activation levels (and therefore force output) in three upper limb muscles, the abductor digiti minimi, flexor pollicis longus and biceps brachii, are significantly influenced by the type of stone tool used during cutting tasks. For each muscle, handaxes are more demanding to use relative to smaller Oldowan and Levallois flake technologies. We argue that these differences could have promoted the production of flake tools over handaxes in some functional contexts, across both the Acheulean and Middle Palaeolithic.

Six of the muscles investigated, however, were not affected by tool type changes. Similarly, no significant differences in muscle activation were observed between Oldowan flakes and Levallois flakes, while Lomekwian flakes displayed no consistent differences with other tool types. Muscular demands do not, therefore, decrease in-line with tool-type changes during the Lower and Middle Palaeolithic periods. We therefore reemphasise the potential role of other factors in influencing technological transitions and tool production choices during this period, and stress that ergonomic factors alone cannot explain the tool use behaviors of early hominins.

Finally, we have demonstrated that across the four stone tool types investigated, muscles responsible for flexion, abduction and adduction of the digits and in-hand manipulation are heavily recruited, and significantly more so than those controlling for movement at the wrist, elbow or shoulder. It is these muscles, therefore, that work hardest during stone tool use and are most likely to be responsible for influencing tool-user 'ease-of-use' perceptions and stone tool ergonomic design features. 
587

588

589

590

591

592

593

594

595

596

597

598

599

600

601

602

603

604

605

606

607

608

609

610

611

612

613

614

615

This research was funded by a British Academy Postdoctoral Fellowship (pf160022) awarded to AK. IF and RH are supported by University of Kent graduate scholarships. Our thanks are extended to all participants who took part. AK is grateful to Tracy Kivell for support during this project. Three anonymous reviewers provided constructive suggestions that allowed us to improve the manuscript. We are grateful for their time and advice.

\section{References}

Adler, D.S., Wilkinson, K.N., Blockley, S., Mark, D.F., Pinhasi, R., Schmidt-Magee, B.A., Nahapetyan, S., Mallol, C., Berna, F., Glauberman, P.J., Raczynski-Henk, Y., Wales, N., Frahm, E., Joris, O., MacLeod, A., Smith, V.C., Cullen, V.L., Gasparian, B., 2014. Early Levallois technology and the Lower to Middle Paleolithic transition in the Southern Caucasus. Science 345 (6204), 1609-1613

Almécija, S., Alba, D., 2014. On manual proportions and pad-to-pad precision grasping in Australopithecus afarensis. Journal of Human Evolution 73, 88-92

Ashton, N., McNabb, J., 1994. Bifaces in perspective. In: Ashton, N., David, A. (Eds.) Stories in Stone: Lithic Studies Society Occasional Paper No. 4, pp. 182-191

Ashton, N., Scott, B., 2016. The British Middle Palaeolithic. Quaternary International 411 (Part A), 6276

Ambrose, S., 2001. Paleolithic technology and human evolution. Science 291 (5509), 1748-1753

Archer, W., Braun, D.R., 2010. Variability in bifacial technology at Elandsfontein, Western cape, South Africa: a geometric morphometric approach. Journal of Archaeological Science 37 (1), 201-209

Baena, J., Navas, C.T., Diaz, S.P., Bustos-Perez, G. Romagnoli, F. 2016. To grip or not to grip: an experimental approach for understanding the use of prehensile areas in Mousterian tools. Boletin de Arqueologia Experimental 11, 200-218

Bar-Yosef, O., 1998. On the nature of transitions: the Middle to Upper Paleolithic and the Neolithic Revolution. Cambridge Archaeological Journal 8 (2), 141-163

Bicho, N., Merreiros, J., Cascalheira, J., Pereira, T., Haws, J., 2015. Bayesian modelling and the chronology of the Portuguese Gravettian. Quaternary International 359-360, 499-509

Bilbao, I., Rios-Garaizar, J., Arrizabalaga, A., 2019. Relationships between size and precision of flake technology in the Middle Paleolithic. An experimental study. Journal of Archaeological Science Reports 25, 530-547 
Boëda, E., 1995. Levallois: a volumetric construction, methods, a technique. In: Dibble HL, Bar-Yosef O, editors. The Definition and Interpretation of Levallois Technology. Madison: Prehistory Press. pp. $41-68$

Borel, A., Cheze, L., Pouydebat, E., 2016. Sequence analysis of grip and manipulation during tool using tasks: a new method to analyze hand use strategies and examine human specificities. Journal of Archaeological Method and Theory 24 (3), 751-775

Boucher de Perthes J., 1847. Antiquités Celtiques at Antédiluviennes. Treuttel and Wurtz, Paris

Brantingham, P.J., Kuhn, S.L., 2001. Constraints on Levallois Core Technology: A Mathematical Model. Journal of Archaeological Science 28 (7), 747-761

Braun, D.R., Aldeias, V., Archer, W., Arrowsmith, J.R., Baraki, N., Campisano, C.J., Deino, A.L., DiMaggio, E.N., Dupont-Nivet, G., Engda, B., Feary, D.A., Garello, D.I., Kerfelew, Z., McPherron, S.P., Patterson, D.B., Reeves, J.S., Thompson, J.C., Reed, K.E., 2019. Earliest known Oldowan artifacts at $>2.58$ Ma from Ledi-Geraru, Ethiopia, highlight early technological diversity. PNAS, 1820177116

Camps, M., Chauhan, P.R. 2011. Sourcebook of Paleolithic Transitions. Springer, New York

Clancy, E.A., Negro F., Farina, D., 2016. Single-channel techniques for information extraction from the surface EMG signal. In: Merletti, R., Farina, D. (Eds.) Surface Electromyography: Physiology, Engineering, and Applications. Wiley and Sons, Hoboken. pp. 91-125

Clark, J.D., 1987. Transitions: Homo erectus and the Acheulian: the Ethiopian sites of Gadeb and the Middle Awash. Journal of Human Evolution 16 (7-8), 809-826

Claud, E., 2015. The use of biface manufacturing flakes: Functional analysis of three Middle Paleolithic assemblages from southwestern and northern France. Quaternary International 361, 131-141

Dennell, R. 2017. Human colonization of Asia in the late Pleistocene. Current Anthropology 58, 383396

Dibble, H.L., Bernard, M.C., 1980. A comparative study of basic edge angle measuring techniques. American Antiquity 45 (4), 857-865

Diez-Martin, F., Yustos, P.S., Uribelarrea, D., Baquedano, E., Mark, D.F., Mabulla, A., Fraile, C., Duque, J., Diaz, I., Perez-Gonzalez, A., Yravedra, J., Egeland, C.P., Organista, E., Dominguez-Rodrigo, M., 2015. The origin of the Acheulean: the 1.7 million-year-old site of FLK West, Olduvai Gorge (Tanzania). Scientific Reports 5, 17839

Diogo, R., Richmond, B.G., Wood, B., 2012. Evolution and homologies of primate and modern human hand and forearm muscles, with notes on thumb movements and tool use. Journal of Human Evolution $63,64-78$ 
648 Domalain, M., Bertin, A., Daver, G., 2017. Was Australopithecus afarensis able to make the 649 Lomekwian stone tools? Towards a realistic biomechanical simulation of hand force capability in fossil 650 hominins and new insights on the role of the fifth digit. Comptes Rendus Palevol 16 (5-6), 572-584

651 Enola, R.M., Duchateau, J., 2016. Physiology of muscle activation and force generation. In: Merletti, 652 R., Farina, D. (Eds.) Surface Electromyography: Physiology, Engineering, and Applications. Wiley and 653 Sons, Hoboken. pp. 1-29

654 Emory, K., 2010. A re-examination of variability in handaxe form in the British Palaeolithic. Ph.D. 655 Thesis, University College London

656 Eren, M.I. 2013. The technology of Stone Age colonization: an empirical, regional-scale examination 657 of Clovis unifacial stone tool reduction, allometry, and edge angle from the North American Lower 658 Great Lakes region. Journal of Archaeological Science 40 (4), 2101-2112

659 Eren, M.I., Lycett, S.J., 2012. Why Levallois? A morphometric comparison of experimental 660 'preferential' Levallois flakes versus debitage flakes. PLOS ONE 7(1), e29273

661 Eren, M.I., Lycett, S.J., 2016. A statistical examination of flake edge angles produced during 662 experimental lineal Levallois reductions and consideration of their functional implications. Journal of 663 Archaeological Method and Theory 23 (1), 379-398

664 Eren, M.I., Lycett, S.J., Patten, R.J., Buchanan, B., Pargeter, J., O’Brien, M.J., 2016. Test, model, and 665 method validation: the role of experimental stone artifact replication in hypothesis driven archaeology. 666 Ethnoarchaeology 8 (2), 103-136

667 Evans J., 1872. The Ancient Stone Implements, Weapons and Ornaments of Great Britain. Longmans, 668 Green and Co., London

669 Faisal, A., Stout, D., Apel, J., Bradley, B., 2010. The manipulative complexity of Lower Paleolithic 670 stone toolmaking. PLOS ONE 5 (11), e13718

671 Farina, D., Stegeman, D.F., Merletti, R., 2016. Biophysics of the generation of EMG signals. In: 672 Merletti, R., Farina, D. (Eds.) Surface Electromyography: Physiology, Engineering, and Applications. 673 Wiley and Sons, Hoboken. pp. 30-53

674 Feix, T., Kivell, T.L., Pouydebat, E., Dollar, A.M., 2015. Estimating thumb-index finger precision grip 675 and manipulation potential in extant and fossil primates. Journal of the Royal Society Interface 12 (106), 67620150176

677 Feuerriegel, E., 2016. Biomechanics of the hominin upper limb: entheseal development and stone tool 678 manufacture. Ph.D. Thesis, Australian National University 
679 Feuerriegel, E.M., Voisin, J.-L., Churchill, S.E., Haeusler, M., Mathews, S., Schmid, P., Hawks, J., 680 Berger, L.R., 2019. Upper limb fossils of Homo naledi from the Lesedi Chamber, Rising Star System, 681 South Africa. Paleoanthropology 2019, 311-349

682 Freund, J., Takala, E.P., Toivonen, R., 2000. Effects of two ergonomic aids on the usability of an in683 line screwdriver. Applied Ergonomics 31 (4), 371-376

684 Foley, R., Lahr, M.M., 2003. On stony ground: lithic technology, human evolution, and the emergence 685 of culture. Evolutionary Anthropology 12, 109-122

686 Galán, A.B., Domínguez-Rodrigo, M., 2014. Testing the efficiency of simple flakes, retouched flakes, 687 and handaxes during butchery. Archaeometry 56 (6), 1054-1074

688 García-Medrano, P., Ollé, A., Ashton, N., Roberts, M.B., 2019. The mental template in handaxe 689 manufacture: new insights into Acheulean lithic technologic behaviour at Boxgrove, Sussex, UK. 690 Journal of Archaeological Method and Theory 26 (1), 396-422

691 Gazzoni, M., Afsharipour, B., Merletti, R., 2016. Surface EMG in ergonomics and occupational 692 medicine. In: Merletti, R., Farina, D. (Eds.) Surface Electromyography: Physiology, Engineering, and 693 Applications. Wiley and Sons, Hoboken. pp. 54-90

694 Goren-Inbar, N., Saragusti, I., 1996. An Acheulian biface assemblage from Gesher Benot Ya'aqov, 695 Israel: indications of African affinities. Journal of Field Archaeology 23 (1), 15-30

696 Gowlett, J.A.J., 2006. The elements of design form in Acheulean bifaces: modes, modalities, rules and 697 language. In N. Goren-Inbar \& G. Sharon (eds): Axe Age: Acheulian Tool-Making From Quarry to 698 Discard, pp. 203-221. Equinox, London

699 Gowlett, J.A.J., 2009. The longest transition or multiple revolutions? Curves and steps in the record of 700 human origins. In M. Camps \& P. Chauhan (eds): Sourcebook of Paleolithic Transitions, pp. 65-78. 701 Springer, New York Gowlett, J.A.J., 2013. Elongation as a factor in artefacts of humans and other animals: an Acheulean example in comparative context. Phil. Trans. R. Soc. B. 368, 20130114 Gorsman, L., Goldsmith, Y., Smilansky, U., 2011. Morphological analysis of Nahal Zihor handaxes: a chronological perspective. PaleoAnthropology 2011, 203-215

Grant, K.A., Habes, D.J., 1997. An electromyographic study of strength and upper extremity muscle activity in simulated meat cutting tasks. Applied Ergonomics 28 (2), 129-137 longus muscle: implications for the evolution of hominid tool use. Journal of Human Evolution 34 (2), 
Hardy, B.L., Moncel, M.-H., Despriee, J., Courcimault, G., Voinchet, P., 2018. Middle Pleistocene hominin behaviour at the 700ka Acheulean site of la Noira (France). Quaternary Science Reviews 199, $60-82$

Harmand, S., Lewis, J.E., Feibel, C.S., Lepre, C.J., Prat, S., Lenoble, A., Boes, X., Quinn, R.L., Brenet, M., Arroyo, A., Taylor, N., Clement, S., Daver, G., Brugal, J.-P., Leakey, L., Mortlock, R.A., Wright, J.D., Lokorodi, S., Kirwa, C., Kent, D.V., Roche, H., 2015. 3.3-million-year-old stone tools from Lomekwi 3, West Turkana, Kenya. Nature 521, 310-315

Hermens, H. J., Freriks, B., Disselhorst-Klug, C., Rau, G., 2000. Development of recommendations for SEMG sensors and sensor placement procedures. Journal of Electromyography and Kinesiology 10 (5), 361-374

Herzlinger, G., Goren-Inbar, N., 2019. Beyond a cutting edge: a morpho-technological analysis of Acheulian handaxes and cleavers from Gesher Benot Ya'aqov, Israel. Journal of Paleolithic Archaeology 3, 33-58

Iovita, I., 2014. The role of edge angle maintenance in explaining technological variation in the production of Late Middle Paleolithic bifacial and unifacial tools. Quaternary International 350, 105115

Isaac, B. 1989. The Archaeology of Human Origins: Papers by Glynn Isaac. Cambridge University Press, Cambridge

Isaac, G., 1969. Studies of early culture in East Africa. World Archaeology 1 (1), 1-28

Jobson, R.W., 1986. Stone tool morphology and rabbit butchery. Lithic Technology 15, 9-20

Jones, P., 1980. Experimental butchery with modern stone tools and its relevance for Palaeolithic archaeology. World Archaeology 12 (2), 153-165

Jones, P.R., 1981. Experimental implement manufacture and use; a case study from Olduvai Gorge, Tanzania. Phil. Trans. R. Soc. B. 292, 189-195

Jones, P., 1994. Results of experimental work in relation to the stone industries of Olduvai Gorge. In: Leakey MD (ed) Olduvai Gorge: Excavations in Beds III, IV and the Masek Beds 1968-1971. Cambridge University Press, Cambridge

Key, A.J.M., 2016. Integrating mechanical and ergonomic research within functional and morphological analyses of lithic cutting technology: Key principles and future experimental directions. Ethnoarchaeology 8 (1), 69-89

Key, A.J.M., Dunmore, C.J., 2018. Manual restrictions on Palaeolithic technological transitions. PeerJ 6, e5399 
Key, A.J.M., Lycett, S.J., 2017a. Form and function in the Lower Palaeolithic: history, progress, and continued relevance. Journal of Anthropological Sciences 95, 67-108

Key, A.J.M., Lycett, S.J., 2017b. Reassessing the production of handaxes versus flakes from a functional perspective. Archaeological and Anthropological Sciences 9 (5), 737-753

Key, A.J.M., Lycett, S.J., 2017c. Influence of handaxe size and shape on cutting efficiency: a large scale experiment and morphometric analysis. Journal of Archaeological Method and Theory 24 (2), $514-541$

Key, A.J.M., Lycett, S.J., 2018. Investigating interrelationships between Lower Palaeolithic stone tool effectiveness and tool user biometric variation: implications for technological and evolutionary changes. Archaeological and Anthropological Sciences 10 (5), 989-1006

Key, A.J.M., Proffitt, T., Stefani, E., Lycett, S.J., 2016. Looking at handaxes form another angle: assessing the ergonomic and functional importance of edge form in Acheulean bifaces. Journal of Anthropological Archaeology 44, 43-55

Key, A.J.M., Merritt, S.R., Kivell, T.L., 2018. Hand grip diversity and frequency during the use of Lower Palaeolithic stone cutting-tools. Journal of Human Evolution 125, 137-158

Key, A., Young, J., Fisch, M.R., Chaney, M.E., Kramer, A., Eren, M.I., 2018. Comparing the use of meat and clay during cutting and projectile research. Engineering Fracture Mechanics 192, 163-175

Kivell, T.L., 2015. Evidence in hand: recent discoveries and the early evolution of human manual manipulation. Phil. Trans. R. Soc. B. 370, 20150105

Kleindienst, M.R., Keller, C.M., 1976. Towards a functional analysis of handaxes and cleavers: the evidence from Eastern Africa. Man 11 (2), 176-187

Leakey, M.D., 1971. Olduvai Gorge. Excavations in Beds I \& II 1960 - 1963. Cambridge University Press

Lewis, J.R., Harmand, S., 2016. An earlier origin for stone tool making: implications for cognitive evolution and the transition to Homo. Phil. Trans. R. Soc. B 371 (1698), 2015.0233

Lin, S.C., 2018. Flake selection and scraper retouch probability: an alternative model for explaining Middle Paleolithic assemblage retouch variability. Archaeological and Anthropological Sciences 10 (7), $1791-1806$

Lin, S.C., Rezek, Z., Dibble, H.L., 2018. Experimental design and experimental inference in stone artifact archaeology. Journal of Archaeological Method and Theory 25 (3), 663-688 
Lycett, S.J., von Cramon-Taubadel, N., Gowlett, J.A.J., 2010. A comparative 3D geometric morphometric analysis of Victoria West cores: implications for the origins of Levallois technology. Journal of Archaeological Science 37 (5), 1110-1117

Lycett, S.J., Eren, M.I., 2013. Levallois economics: an examination of 'waste' production in experimentally produced Levallois reduction sequences. Journal of Archaeological Science 40 (5), $2384-2392$

Lycett, S.J., Eren, M.I., 2013. Levallois lessons: the challenge of integrating mathematical models, quantitative experiments and the archaeological record. World Archaeology 45 (4), 519-538

Lycett, S.J., Gowlett, J.A.J., 2008. On questions surrounding the Acheulean 'tradition'. World Archaeology 40 (3), 295-315

Malinsky-Buller, A., 2016. Lost and found: Technological trajectories within Lower/Middle Paleolithic transition in Western Europe, North of the Pyrenees. Quaternary International 409 (Part B), 104-148

Marzke, M.W., 1983. Joint functions and grips of the Australopithecus afarensis hand, with special reference to the region of the capitate. Journal of Human Evolution 12 (2), 197-211

Marzke, M.W., 1997. Precision grips, hand morphology, and tools. American Journal of Physical Anthropology 102 (1), 91-110

Marzke, M.W. 2013. Tool making, hand morphology and fossil hominins. Philosophical Transactions of the Royal Society B 368, 20120414

Marzke, M.W., Shackley, M.S., 1986. Hominid hand use in the Pliocene and Pleistocene: evidence from experimental archaeology and comparative morphology. Journal of Human Evolution 15 (6), 439460

Marzke, M.W., Toth, N., Shick, K., Reece, S., Steinberg, B., Hunt, K., Linscheid, R.L., An, K.-N., 1998. EMG study of hand muscle recruitment during hard hammer percussion manufacture of Oldowan tools. American Journal of Physical Anthropology 105 (3), 315-332

McCall, G.S., 2005. An experimental examination of the potential function of Early Stone Age tool technology and implications for subsistence behaviour. Lithic Technology 30 (1), 29-43

McNabb, J., 2005. Hominins and the Early-Middle Pleistocene transition: evolution, culture and climate in Africa and Europe. In: Head, M.J., Gibbard, P.L. (Eds.) Early-Middle Pleistocene Transitions: The Land-Ocean Evidence. Geological Society, London. pp. 287-304

Merletti, R., Botter, A., Barone, U., 2016. Detection and conditioning of surface EMG signals. In: Merletti, R., Farina, D. (Eds.) Surface Electromyography: Physiology, Engineering, and Applications. Wiley and Sons, Hoboken. pp. 54-90 
Mersey, B., Jabbour, R.S., Brudvik, K., Defleur, A., 2013. Neanderthal hand and foot remains from Moula-Guercy, Ardeche, France. American Journal of Physical Anthropology 152 (4), 516-529

Mihailovic, D., BogiCevic, K., 2017. Technological changes and population movements in the Late Lower and Early Middle Paleolithic of the Central Balkans. In: Harvati, K., Roksandic, M. (Eds.) Paleoanthropology of the Balkans and Anatolia. Springer, Dordrecht. pp. 139-152

Milner-Brown, H. S., Stein, R. B., Yemm, R., 1973. Changes in firing rate of human motor units during linearly changing voluntary contractions. Journal of Physiology 23 (2), 371-390.

Moncel, M.-H., Moigne, A.-M., Sam Y., Combier, J., 2011. The emergence of Neanderthal technical behaviour: new evidence from Orgnac 3 (Level 1, MIS 8), Southeastern France. Current Anthropology $52(1), 37-75$

Moncel, M.-H.,, Moigne, A.-M., Combier, J., 2012. Towards the Middle Palaeolithic in Western Europe: the case of Orgnac 3 (southeastern France). Journal of Human Evolution 63 (5), 653-666

Muller, A., Clarkson, C., 2016. Identifying major transitions in the evolution of lithic cutting edge production rates. PLOS ONE 11 (12), e0167244

Niewoehner, W.A., 2001. Behavioral inferences from the Skhul / Qafzeh early modern human hand remains. PNAS 98 (6), 2979-2984

Ollé, A., Mosquera, M., Rodriguez, X.P., de Lombera-Hermida, A., Garcia-Anton, M.D., GarciaMedrano, P., Pena, L., Menendez, L., Navazo, M., Terradillos, M., Bargallo, A., Marquez, B., Sala, R., Carbonell, E., 2013. The Early and Middle Pleistocene technological record from Sierra de Atapuerca (Burgos, Spain). Quaternary International 295, 138-167

Pargeter, J., Khreisheh, N., Stout, D., 2019. Understanding stone tool-making skill acquisition: experimental methods and evolutionary implications. Journal of Human Evolution 133, 146-166

Phillipson, L., 1997. Edge modification as an indicator of function and handedness of Acheulian handaxes from Kariandusi, Kenya. Lithic Technology 22 (2), 171-183

Pontonnier, C., Dumont, G., de Zee, M., Samani, A., Madeleine, P., 2012. Cutting force and EMG recordings for ergonomic assessment of meat cutting tasks: influence of the workbench height and the cutting direction on muscle activation. Proceedings of the 11th Biennial Conference On Engineering Systems Design And Analysis, 00762797

Prasciunas, M.M., 2007. Bifacial cores and flake production efficiency: an experimental test of technological assumptions. American Antiquity 72 (2), 334-348 
Proffitt, T., 2018. Is there a developed Oldowan A at Olduvai Gorge? A diachronic analysis of the Oldowan in Bed I and Lower-Middle Bed II at Olduvai Gorge, Tanzania. Journal of Human Evolution $120,92-113$

Rezek, Z., Dibble, H.L., McPherron, S.P., Braun, D.R., Lin, S.C., 2018. Two million years of flaking stone and the evolutionary efficiency of stone technology. Nature Ecology and Evolution 2, 628-633

Roche, H., Delagnes, A., Brugal, J.-P., Feibel, C., Kibunjia, M., Mourre, V., Texier P.-J., 1999. Early hominid stone tool production and technical skill 2.34 Myr ago in West Turkana, Kenya. Nature 399, $57-60$

Rogers, M.J., Semaw, S., 2009. From nothing to something: the appearance and context of the earliest archaeological record. In: Camps, M., Chauhan, P.R. (Eds.) Sourcebook of Palaeolithic transitions: Methods, Theories, and Interpretations. Springer, New York. pp. 155-171

Rolian, C., Lieberman, D.E., Zermeno, J.P., 2011. Hand biomechanics during simulated stone tool use. Journal of Human Evolution 61 (1), 26-41

Rots, V., 2013. Insights into early Middle Palaeolithic tool use and hafting in Western Europe. The functional analysis of level IIa of the early Middle Palaeolithic site of Biache-Saint-Vaast (France). Journal of Archaeological Science 40 (1), 497-506

Ruebens, K., 2013. Regional behaviour among late Neanderthal groups in Western Europe: a comparative assessment of late Middle Palaeolithic bifacial tool variability. Journal of Human Evolution 65 (4), 341-362

Semaw S., Rogers M., Stout D., 2009. The Oldowan-Acheulian transition: Is there a "Developed Oldowan" artifact tradition?. In M. Camps \& P. Chauhan (eds): Sourcebook of Paleolithic Transitions, pp. 173-193. Springer, New York

Semaw, S., Rogers, M.J., Caceres, I., Stout, D., Leiss, A.C., 2018. The early Acheulean 1.6-1.2 Ma from Gona, Ethiopia: Issues related to the emergence of the Acheulean in Africa. In: Gallotti, R., Mussi, M. (Eds.) The Emergence of the Acheulean in East Africa and Beyond. Springer Nature, Cham. pp. $115-128$

Sharon, G., 2010. Large flake Acheulian. Quaternary International 223-224, 226-233

Shea, J., 2007. Lithic technology, or, what stone tools can (and can't) tell us about early hominin diets. In P.S. Ungar (ed): Evolution of the Human Diet: The Known, the Unknown, and the Unknowable, pp. 212-229. Oxford University Press, Oxford.

Shea, J., 2017. Occasional, obligatory, and habitual stone tool use in hominin evolution. Evolutionary Anthropology 26, 200-217 
Shimelmitz, R., Weinstein-Evron, M., Ronen, A., Kuhn, S.L., 2016. The Lower to Middle Paleolithic transition and the diversification of Levallois technology in the Southern Levant: Evidence from Tabun Cave, Israel. Quaternary International 409 (Part B), 23-40

Shipton, C., 2016. Hierarchical organization in the Acheulean to Middle Palaeolithic transition at Bhimbetka, India. Cambridge Archaeological Journal 26 (4), 601-618

Shipton, C., Clarkson, C., Pal, N.J., Jones S.C., Roberts, R.G., Harris, C., Gupta, M.C., Ditchfield. P.W., Petraglia, M.D., 2013. Generativity, hierarchical action and recursion in the technology of the Acheulean to Middle Palaeolithic transition: A perspective from Patpara, the Son Valley, India. Journal of Human Evolution 65 (2), 93-108

Stegeman, D., Hermens, H., 2007. Standards for surface electromyography: The European project Surface EMG for non-invasive assessment of muscles (SENIAM). Enschede: Roessingh Research and Development, 108-112.

Stout, D., Toth, N., Schick, K., Chaminade, T., 2008. Neural correlates of Early Stone Age toolmaking: technology, language and cognition in human evolution. Phil. Trans. R. Soc. B 363, 1939-1949

Tocheri, M., Orr, C.M., Jacofsky, M.C., Marzke, M.W., 2008. The evolutionary history of the hominin hand since the last common ancestor of Pan and Homo. Journal of Anatomy 212 (4), 544-562

Tomka, S.A., 2001. The effect of processing requirements on reduction strategies and tool form: a new perspective. In: Andrefsky J. (Ed.) Lithic Debitage: Context, Form, Meaning. The University of Utah Press, Salt Lake City. pp. 207-225

de la Torre, I., 2016. The origins of the Acheulean: past and present perspectives on a major transition in human evolution. Phil. Trans. R. Soc. B, 371, 20150245

Toth, N., 1985. The Oldowan reassessed: a close look at early stone age artifacts. Journal of Archaeological Science 12 (2), 101-120

Toth, N., Schick, K., 2009. The importance of actualistic studies in early Stone Age research: some personal reflections. In K. Schick \& N. Toth (Eds.), The Cutting Edge: New Approaches to the Archaeology of Human Origins. Gosport: Stone Age Institute Press. pp. 267-344

Tryon, C.A., Faith, J.T., 2013. Variability in the Middle Stone Age of Eastern Africa. Current Anthropology 54 (8), 234-254

Tryon, C.A., McBrearty, S., Texier, P.-J., 2006. Levallois lithic technology from the Kapthurin Formation, Kenya: Acheulian origin and Middle Stone Age diversity. African Archaeological Review, $22(4), 199-229$ 
898 Van Peer, P., Fullagar, R., Stokes, S., Bailey, R.M., Moeyersons, J., Steenhoudt, F., Geerts, A., 899 Vanderbeken, T., De Dapper, M., Geus, F., 2003. The Early to Middle Stone Age transition and the 900 emergence of modern human behaviour at site 8-B-11, Sai Island, Sudan. Journal of Human Evolution $90145(2), 187-193$

902 Viallet, C., 2016. Bifaces used for percussion? Experimental approach to percussion marks and 903 functional analysis of the bifaces from Terra Amata (Nice, France). Quaternary International 406, 174$904 \quad 181$

905 Ward, C.V., Tocheri, M.W., Plavcan, J.M., Brown, F.H., Manthi, F.K., 2014. Early Pleistocene third 906 metacarpal from Kenya and the evolution of modern human-like hand morphology. PNAS 111 (1), $907 \quad 121-124$

908 Williams-Hatala, E.M., Hatala, K.G., Gordon, M., Key, A., Kasper, M., Kivell, T.L., 2018. The manual 909 pressures of stone tool behaviors and their implications for the evolution of the human hand. Journal of 910 Human Evolution 119, 14-26

911 Wynn, T., Coolidge, F.L., 2004. The expert Neanderthal mind. Journal of Human Evolution 46 (4), $912 \quad 467-487$

913 Wynn, T., Gowlett, J.A.J., 2018. The handaxe reconsidered. Evolutionary Anthropology 27 (1), 21-29

914 Zupancich, A., Lemorini, C., Gopher, A., Barkai, R., 2016. On Quina and demi-Quina scraper handling: 915 preliminary results from the late Lower Paleolithic site of Qesem Cave, Israel. Quaternary International $916398,94-102$

917

918

919

920

921 
926 Figure 1: The full array of sensors attached to the arm of a participant (A, B). Figure C depicts a

927 participant as they use a handaxe to cut the vertically secured twine segments midway through the task.

928 All sections of the cutting task are displayed in Figure D.

929 Figure 2: Sensors attached above the first dorsal interosseous, highlighting their shape when cut in half 930 to fit above a target muscle.

931 Figure 3: An example of two sEMG signals with amplitude variation at 0.4 second epochs (A), the 932 same signals after band pass filtering between $10 \mathrm{~Hz}$ to $350 \mathrm{~Hz}$ is applied (B), then again expressed as 933 each signal's root mean square (RMS) (C). An example of signal clipping and motion artefact distortion 934 during a flexor pollicis brevis signal recording can be seen in figure $\mathrm{D}$.

935 Figure 4: Examples of the replica Lomekwian (A), Acheulan (B), Levallois (C) and Oldowan (D) tools 936 used in this experiment, alongside the full assemblage of 30 Acheulean handaxes. All other complete 937 assemblages are available in SOM Figure S1. The scale bar is $10 \mathrm{~cm}(\mathrm{~A}, \mathrm{~B}, \mathrm{C}, \mathrm{D})$ or $30 \mathrm{~cm}(\mathrm{E})$ long.

938 Figure 5: Maximum voluntary contraction percentage (\% MVC) values for each of the nine target 939 muscles during the clay-cutting task. Differences can be observed between each muscle dependent on 940 the type of stone tool being used, despite the task being identical in each instance. Activations over $100 \%$ 941 may be possible where the muscle was incompletely activated during the static MVC exercise and a 942 higher activation occurred during the experimental task. 